
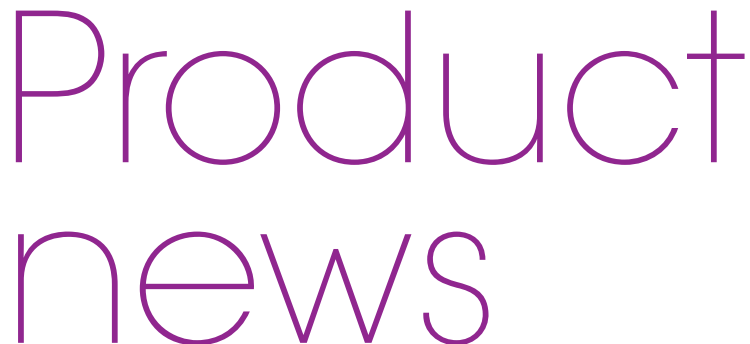

Product news is provided as a service to readers using text and images from

the manufacturer, supplier or distributor and does not imply endorsement

by BDJ Team. Normal and prudent research should be exercised before

purchase or use of any product mentioned

\section{THE FIRST APP OF ITS KIND}

Innovative dental software developers,

Welltime, are excited to announce their latest

helpful solution: the Dental Diary app.

With this easy-to-use and free to download

app, you will be able to access

your entire diary on your

smartphone - whenever you

need to. Syncing with your

practice's existing management software, the Dental Diary

app will update automatically

if appointments are made,

changed or cancelled -

allowing you to stay in

complete control of your

workload.
Featuring 24/7 access, Dental Diary will let you plan your time more effectively. Updating in real time, the app will let you know if your first appointment tomorrow has been cancelled, allowing you to plan your day quickly and simply. What's more, you'll also be able to access your team's diaries, too - meaning your entire practice will run more efficiently than ever.

The Dental Diary app from Welltime is available for download on Android and iPhone; take control of your diary and stay informed at all times. To find out more, contact the expert Welltime team today on 07999991 337, email sales@welltime.co.uk or visit the website at www.welltime.co.uk.

\section{DRY MOUTH IS ON THE RISE}

In a survey of dental professionals, $89 \%$ agree that 'dry mouth is on the rise?.

During February Oralieve asked dental professionals about their experience of patients with dry mouth and the results are in. Out of the 621 dental professionals who answered the survey:

- $80 \%$ of dental professionals are seeing more than five patients a month with dry mouth and $44 \%$ are seeing more than ten a month

- The main causes of dry mouth are: types of medication taken, polypharmacy, Sjögren's syndrome and mouth breathing at night

- $89 \%$ agree dry mouth is on the rise.

Recommend the Oralieve Dry Mouth Relief product range for effective relief from dry mouth. Available from www. oralieve.co.uk and Dental Directory.

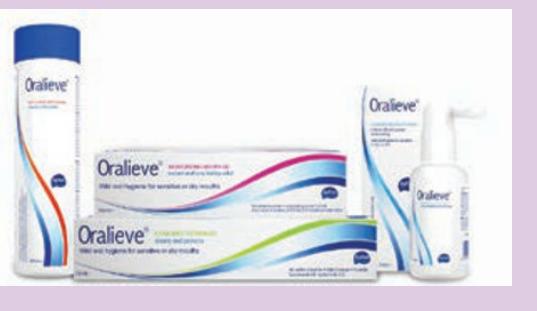

\title{
SURFACE DISINFECTION SURVEY RESULTS
}

A survey recently conducted by Initial Medical (January 2017) confirmed that infection control and prevention protocols are generally very good within dental practices. After asking 131 teams across the UK how often they disinfected different areas of the premises, here are some of the key results (Table 1).
Almost $14 \%$ of the practices surveyed indicated that they give the waiting area a 'deep clean' every day (where furniture is moved round and every nook and cranny is cleaned), while $26 \%$ do it weekly, once a month (20\%), every other month (27\%) and every six months (7\%).

In order to really optimise your surface
Table 1 How often UK dental practices disinfect different areas of the practice $(n=131)$

\begin{tabular}{|c|c|c|c|c|c|}
\hline \multirow[b]{2}{*}{ Area of the dental practice } & \multicolumn{5}{|c|}{ Frequency of cleaning } \\
\hline & Daily & Weekly & Monthly & Never & Other \\
\hline Reception desk & $92 \%$ & $5 \%$ & $1 \%$ & $0 \%$ & $3 \%$ \\
\hline Magazine table in waiting room & $75 \%$ & $12 \%$ & $0 \%$ & $0 \%$ & $14 \%$ \\
\hline Children's play area/equipment & $47 \%$ & $8 \%$ & $1 \%$ & $5 \%$ & $40 \%$ \\
\hline Door handles & $87 \%$ & $9 \%$ & $1 \%$ & $0 \%$ & $3 \%$ \\
\hline $\begin{array}{l}\text { Keypad on the card chip and } \\
\text { pin reader }\end{array}$ & $81 \%$ & $11 \%$ & $2 \%$ & $2 \%$ & $5 \%$ \\
\hline
\end{tabular}

decontamination processes, it's essential to use the most effective products. The new Steri-7 Xtra High Level Disinfectant Cleaner from Initial Medical
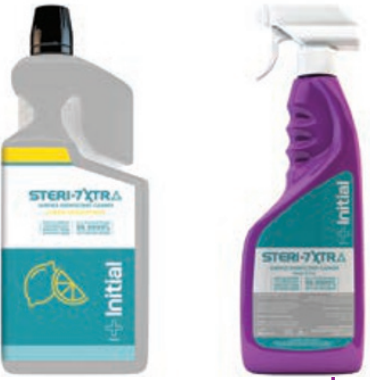
is available as

a concentrate, a ready to use spray and wipes, and has been proven effective against 99.9999\% of bacteria, spores, fungi, yeasts and viruses.

Its innovative 'Reactive Barrier Technology' - a specialised micro emulsion that provides an optional sustained release system - means it continues to work even once dry, keeping treated areas contamination-free for up to 72 hours.

For further information visit www.initial.co.uk/medical or call 0870 8504045 . 